\title{
Urban lead
}

\author{
The world is undergoing a phenomenally fast wave of urban growth. Research that can help tackle some \\ of the ensuing problems is likely to originate in cities themselves.
}

Humanity has evolved into an urban species. Already, more than half the planet's population lives in cities and this fraction is expected to rise to $70 \%$ by 2070 . The speed and scale of urban growth poses significant social, economic and environmental challenges, such as ensuring that the 10 million or so inhabitants of megacities have access to adequate supplies of food and clean water each day. But urban areas also concentrate and foster human ingenuity. Innovative solutions to the problems of the twenty-first century, ranging from climate change and poverty to energy supply, are most likely to be thought up in the stimulating environments that make up urban centres. In this way, cities could help to mitigate the ill effects of an evercrowding planet.

As highlighted in a Book Review on page 733 , it is not only general urbanization that is on the rise. The number of megacities is also set to increase. Some of the fastest urban growth is taking place in developing countries in Asia and Africa, where the reality for many city dwellers is extreme poverty, along with poor sanitation and a shortage of clean water.

As hubs of consumption, transportation and industry, cities release disproportionate amounts of pollutants, such as nitrogen oxides and greenhouse gases. According to one estimate, more than $70 \%$ of energyrelated carbon emissions are generated by urban areas (Nature 467, 900-901; 2010). Cities also generate a tremendous amount of industrial wastewater and sewage that can escape into freshwater and marine systems. The resultant eutrophication, in turn, raises the susceptibility of coastal waters to the acidification that comes with rising concentrations of atmospheric carbon dioxide (see Letter on page 766). Acidification could prove a particular problem in coastal waters lining urban areas where growth has outpaced the development of adequate waste-disposal measures.

In several respects, urban areas are also more susceptible to climate change than the open countryside. With their built-up environment that stores daytime heat for release at night and that seals the surface from moisture exchange, cities tend to be significantly warmer than surrounding rural areas - a phenomenon known as the urban

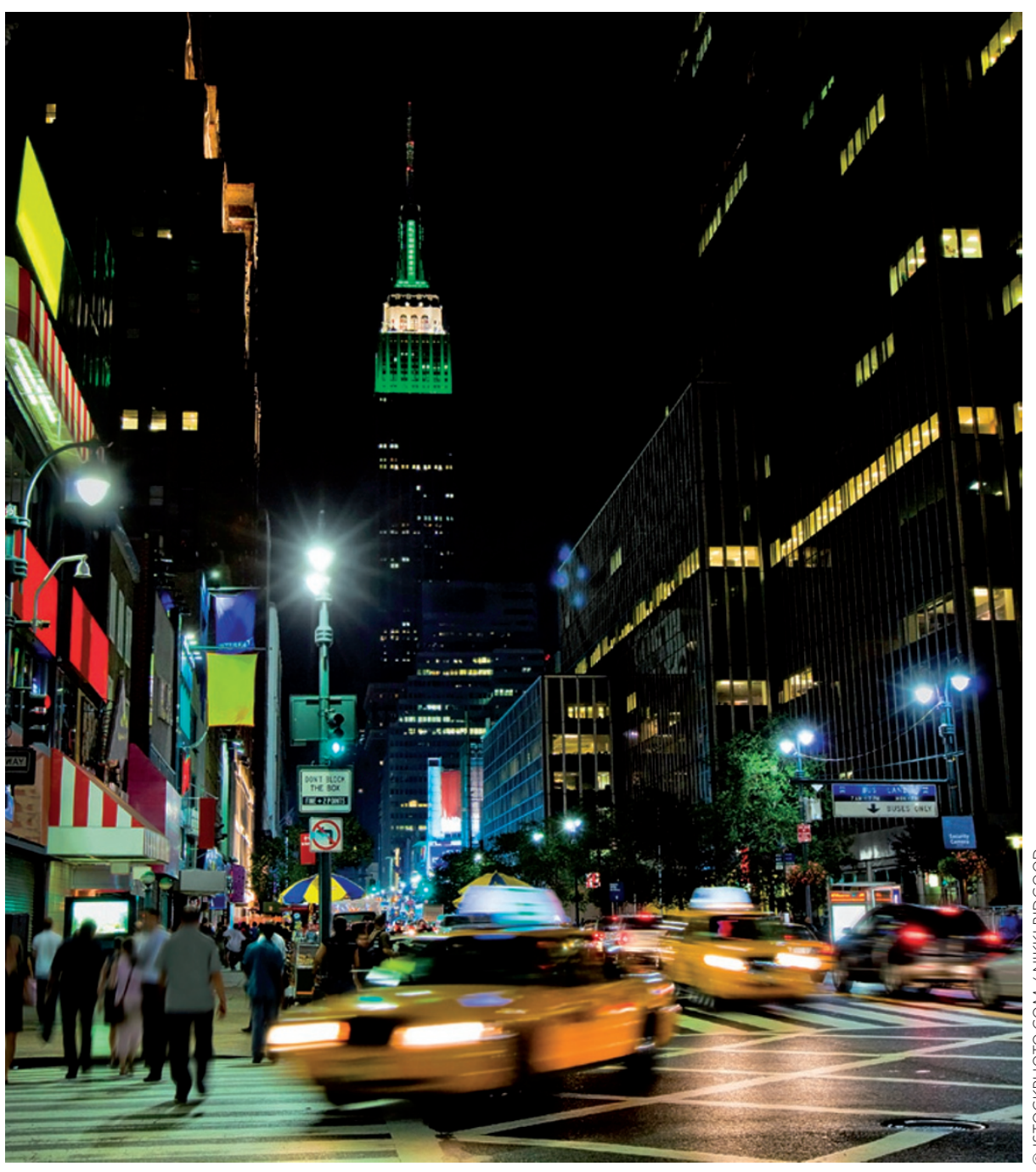

heat island effect. As heatwaves are expected to become more frequent over the coming century, the urban population is at particular risk (Nature Geosci. 3, 398-403; 2010). Furthermore, many large and growing cities are found in river deltas, where sea-level rise adds to their vulnerability (Nature Geosci. 2, 681-686; 2009).

Given the outpouring of pollutants and the vulnerability to climate extremes, city leaders have plenty of reasons to facilitate innovation. Indeed, momentum is mounting for reductions in greenhouse gas emissions at the city level (Nature 467, 909-911; 2010). These efforts from decision makers should be backed up by dedicated research into the impacts of global change on urban areas and mitigation strategies at the city level. As noted in a News \& Views article on page 736, the same measures do not necessarily work on both scales. Whereas white roofing materials help to lower city temperatures, their effect on global temperatures is less certain.

Urbanization shows no sign of slowing down. Political will to tackle some of the ensuing problems seems to be emerging at the city level, but needs to be backed up by a thorough understanding of the threats facing cities, and potential ways forward. Research conducted in cities, and on the topic of cities, will help to bridge this gap. 